\title{
Sociedade Civil e Injustiça ${ }^{1}$
}

\author{
Civil Society and Injustice
}

\author{
JOSÉ JOÃO NEVES BARBOSA VICENTE2 \\ EDVANDRO JESUS DE OLIVEIRA ${ }^{3}$
}

\begin{abstract}
Resumo: O presente trabalho tem como objetivo analisar, a partir de Rousseau, de que maneira o homem vivia no estado natural de natureza e de que forma ele constituiu a sociedade civil ao longo do tempo, construindo assim, as diferentes desigualdades sociais. A partir do momento que o homem passa a desenvolver-se culturalmente, articular a comunicação entre eles e perceber a importância de possuir recursos naturais, começa então, a haver interesses pela dominação desses recursos naturais, o que gerou a formação da propriedade privada como meio de garantia de privilégios e detenção de poder. Contudo, esse fato vai ser mais evidenciado através da organização familiar, pois a partir daí, começa a proteção por esta unidade prioritária, fortalecendo a construção de argumentos que viessem a justificar as desigualdades sociais entre os homens por meio da legitimação de posse e direitos sobre a terra, havendo a relação de dominante e dominado. Com isso, a estrutura social naquele contexto, foi pensada ideologicamente, uma vez que a propriedade privada não surgiu espontaneamente, e sim, das articulações entre os indivíduos que pensaram cautelosamente, gerando dessa maneira, a sociedade de classes, a submissão, dependência e obediência dos tidos como inferiores. Diante disso, percebe-se que, o arranjo social se deu também por meio de lutas, suscitando na dominação dos mais fracos, compondo dessa maneira, uma hegemônica perpetuação dos poderosos.
\end{abstract}

Palavras-chave: Estado de natureza. Dominação. Propriedade privada. Desigualdades.

Abstract: The present work has as objective to analyze, from Rousseau, that way the man lived in the natural state of nature, and how he was civil society over time, building the different social inequalities. From the moment the man going on developing culturally, articulate the communication between them and realize the importance of owning natural resources begins so there is interest for domination of these natural resources, the formation of private property as a guarantee of privileges and holding power. However, this fact will be more evidenced by familiar, because from there, begins this unit priority protection, strengthening the construction of arguments that would justify social inequalities among men through the legitimation of ownership and rights over the land, with the dominant and dominated. With this, the social structure in that context, it was thought ideologically, since private property arose spontaneously, and yes, the joints between the individuals who thought cautiously, generating in this way, the class society, submission, and obedience taken as inferior. Given this, one can see that, the social arrangement has also given through fights, leading in the domination of the weaker, composing in this way, a perpetuation of hegemonic power.

Keywords: State of nature. Domination. Private property. Inequalities.

\footnotetext{
1 Este trabalho é resultado de pesquisa proporcionada pela Bolsa PIBIC/CNPQ concedida ao graduando em Pedagogia, Edvandro de Jesus Oliveira, no período de 2015 a 2016, sob a orientação do professor José João Neves Barbosa Vicente.

2 Professor de Filosofia da Universidade Federal do Recôncavo da Bahia. E-mail: josebvicente@bol.com.br

3 Estudante do Curso de Licenciatura em Pedagogia pela Universidade Federal do Recôncavo da Bahia (UFRB). E-mail: edva.ndro@hotmail.com
} 
O presente artigo pretende investigar, a partir de Rousseau, como se deu a(s) injustiça(s) social(is) entre os homens, valendo-se para isso, do retorno à história do homem no seu estado natural de natureza, a fim de entender como era a vida dos seres humanos em determinado período histórico e como essas pessoas passaram a sair do possível "determinismo natural", sendo que aos poucos, foram organizando-se sistematicamente, tomando uma nova configuração para a garantia da sobrevivência. Enquanto ser dotado de inteligência, com grandes capacidades de adaptação e de sobrevivência em lugares adversos, o ser humano foi percebendo a importância do conhecimento para garantir maior proteção e perpetuação da espécie em meio às adversidades naturais. Essa conjuntura, fez com que o homem estruturasse seus símbolos, bem como um meio que garantisse a comunicação entre os diversos. Para tanto, foi necessário que os indivíduos desenvolvessem uma linguagem comunicativa para que houvesse uma interação mais significativa entre eles.

Contudo, os processos racionais e sociais não ocorreram do nada, pois, os argumentos justificadores de posse e de superioridade tiveram justificativas plausíveis, que é validada pela utilização do pensamento, obtendo assim, poder para manipulação de muitas pessoas, de forma que, os tidos como superiores, justificariam de alguma forma a supremacia das diferenças na garantia de privilégios. É de fundamental importância perceber que, no estado natural de natureza, os homens viviam ajudando-se harmonicamente, pois, não se tinha um sentimento de superioridade, uma vez que, todos desfrutavam dos espaços em que ocupavam de forma comunal, sem maiores intencionalidades até então. Em certa medida, as relações se davam de forma pacífica, justamente por viverem em coletividade, para tanto, os grupos faziam todas as funções de modo a beneficiar a todos. A partir das leituras e reflexões feitas, foi possível analisar e perceber que, a sociedade civil e as injustiças sociais na própria sociedade, foram sem dúvida alguma, algo arquitetado pelo homem, principalmente por meio de discursos que serviram para apropriação dos recursos naturais, se valendo para isso, de falas convincentes quando não por meio de batalhas. Para tais conquistas, como já mencionado, usou-se a força física para dominar, tornando-se assim, detentor de um poder arquitetado capaz de modelar a sociedade de acordo com seus interesses pessoais, grupais, culturais, políticos, econômicos, entre outros.

Dando sequência à discussão, não menos importante que os outros argumentos acima mencionados, cabem também evidenciar que, durante a pesquisa, reflexão e abordagem sobre as diferenças construídas entre os homens, ficou explicito que todas as formas de dominação, só foram plausíveis por meio das relações e construções ideológicas entre os sujeitos, o que teve como consequências a constituição "dos donos do poder". Contudo, essa organização desencadeou ao longo história do homem, nos apropriados e expropriados dos meios de produção. Todos esses fatores se intercruzam para tentar compreender como se deu o processo de acumulação 
primitiva dos bens entre os homens e como foram moldando as relações sociais entre os sujeitos com diferentes interesses.

Desde o surgimento do homem na terra e sua localização pelo espaço terrestre, foi preciso lutar constantemente para manter sua sobrevivência e dos demais, diante disso, ele veio lutando contra vários tipos de adversidades, a fim de, garantir a perpetuação de sua espécie. Esse fato foi algo que exigiu superar os limites impostos pelos meios naturais, dessa forma: "os homens permaneciam, ainda, nos bosques tropicais ou subtropicais e viviam, pelo menos parcialmente, nas árvores, só isso explica que continuasse a existir, em meio a grandes feras selvagens" (ENGELS, 1984, p. 22). Esse fato contribuiu para a formação de grupos de pessoas por meio de inúmeras técnicas, que passou a servir de suporte para vencer o determinismo geográfico natural daquele contexto, garantindo assim, os meios para a evolução intelectual a ponto de utilizar as ideias construídas ao longo do tempo para dominar, explorar e construir leis, a fim de regulamentar o que antes era desorganizado, e acima de tudo, exercer poder também sobre outros seres humanos e até em certa medida a natureza.

Partindo para um maior detalhamento sobre a história do homem, nota-se que, a partir da utilização da linguagem como forma de comunicação interacional, se iniciou entre eles, acordos que foram se estabelecendo por meio do uso da inteligência, fazendo com que grupos mais bem articulados se sobressaíssem a ponto de exercer fortes influências sobre aqueles que não tinham maior articulação das ideias, contudo, pôde-se perceber que, com as disputas pelas propriedades e suas riquezas, fez com que o homem visse em seu semelhante um adversário em potencial, sendo preciso dominá-lo para chegar ao objetivo daquilo que era almejado, para isso, não mediariam esforços para concretizar os objetivos arquitetados. Diante dos sentimentos de importância, o homem já começava a romper com certos obstáculos que pareciam até então intransponíveis e criar estratégias para garantir a proteção e a sobrevivência por meio da ocupação de novos ambientes. Diante disso:

O povoamento de novos lugares e o incessante afã de novos descobrimentos, ligados à posse, que se obtinha pelo atrito, levaram ao emprego de novos alimentos, como as raízes e os tubérculos farináceos, cozidas em cinza quente ou em buracos no chão, e também a caça, que com a invenção das primeiras armas - a clava e a lança - chegou a ser um alimento suplementar ocasional (ENGELS, 1984, p. 23).

Ora, é de extrema relevância perceber que, naquele momento, já começava a haver certa delimitação do espaço de atuação daquelas pessoas (grupos), o que incorre evidentemente em superioridade entre eles, uma vez que, os tidos como menos "avançados" deveriam se submeter aos mais fortes, afim de não perecerem. Mas, esse processo de pensar as mais diferentes articulações, não se deu da noite para 
o dia, ao contrário, foi preciso desenvolver meios, estratégias que garantissem uma comunicação eficiente, para que a partir de então, uns pudessem se destacar em detrimento de outros. Para comprovar essa veracidade, a linguagem não deve ser interpretada como simples formas de sons desprovidas de intencionalidades, sendo que, por meio dela (a linguagem), o sujeito passa a expressar-se sobre o que pensa, buscando interagir com os demais, tanto para dominar, quanto para buscar formas pacíficas de convivências. Fazendo uma relação com o domínio da propriedade, é por meio da articulação dos pensamentos e através da linguagem que acabou gerando uma série de desigualdades sociais, pois é preciso entender que, o desenvolvimento das estruturas mentais mais elevadas do homem, só se tornou possível por meio de reflexões que levaram a ações intencionais e diretivas em busca de seus objetivos, não se importando dessa maneira, o que tal ato poderia significar para outros indivíduos envolvidos, mais sim, exercer sua vontade por meio de um poder articuladamente reconhecido e legitimado. Diante disso, Rousseau declara que:

O primeiro que, tendo cercado um terreno, atreve-se a dizer: Isto é meu, e encontrou pessoas simples o suficiente para acreditar nele, foi o verdadeiro fundador da sociedade civil. Quantos crimes, guerras, assassínios, quantas misérias e horrores não teria poupado o gênero humano aquele, que, arrancando as estacas ou enchendo o fosso, houve gritado aos seus semelhantes: "Evitais ouvir esse impostor" (ROUSSEAU, 1999, p. 204).

Em meio a essa situação, a questão daquilo que era tido comum a todos, passa nesse instante, por uma nova reconfiguração, afim de que, cada um pudesse buscar agora um maior conforto e desfrutar de certo poder por meio da propriedade privada, deixando de lado a ajuda a seu semelhante, pois, o que se tinha em mente era a concorrência pelo bem-estar de poucos e não da coletividade, como se estruturava anteriormente. Segundo Rousseau, isso se deu mais fortemente à medida que o homem passou a constituir-se em núcleo familiar e querer um lugar para viver de forma “isolada”, não de qualquer jeito, pois, a família nesse caso, se tronava uma constituição de laços pessoais em que se desenvolveriam relações que diferenciaria dos demais indivíduos, focando-se agora, nas relações de pai, filho, marido, esposa, entre outros. Mediante a isso, as justificativas de posse, garantiria a muitas pessoas uma perpetuação hegemônica de importância inestimável por meio de posses, o que não seria possível sem outras pessoas que os apoiassem e sustentasse a ideia, resultando assim, na normatização e justificação das desigualdades. Nessas circunstâncias, Rousseau (1999) vem afirmando que as diferenças entre os homens também se deram a partir da valorização de suas qualidades, passando a fazer parte de um conjunto privilegiado, enquanto outros não reconhecidos por esses grupos passaram a ser relegados e deixados ao ostracismo, restando-lhes apenas à submissão. Como já mencionado, o homem passa a se organizar em grupos, nos quais se identificavam. Mediante a esse contexto, a aproximação familiar também ganhava 
novos contornos e significados, algo que até então não existiam de forma mais aproximada. Sobre essas relações, Rousseau relata que:

Os primeiros desenvolvimentos do coração decorreram de uma situação nova que reunia uma habitação comum, os maridos e as mulheres, os pais e os filhos. O habito de viver junto fez nascer os mais doces sentimentos por ventura conhecidos pelos homens, o amor conjugal e o amor paterno. Cada família tornou-se uma pequena sociedade, ainda mais unidas por serem o apego recíproco e a liberdade aos seus únicos vínculos, foi então que se estabeleceu a primeira diferença na maneira de viver dos dois sexos, que até então tinha apenas uma (ROUSSEAU, 1999, p.208).

É nesse contexto, que há um compartilhamento e ligação entre o homem a mulher e filhos, pois essa separação dos grupos, tidos como comuns, só foi admissível a partir da posse da propriedade. Nessa perspectiva, a imposição e a superioridade não passaram a ser somente por meio das disputas pelas propriedades, mas também, para garantir um patamar de vida elevado, destacando o uso de simbologias, assim como suas representações. De acordo com Leslie White, citado por Laraia:

Todo comportamento humano se origina no uso de símbolos. Foi o símbolo que transformou nossos ancestrais antropoides em homens e fê-los humanos. Todas as civilizações se espalharam e se perpetuaram somente pelo uso de símbolos... Toda cultura depende de símbolos. É o exercício da faculdade de simbolização que cria a cultura e o uso de símbolos que torna possível a sua perpetuação. Sem o símbolo não haveria cultura, e o homem seria apenas animal, não um ser humano... O comportamento é o comportamento simbólico (1986, p. 55).

Diante disso, percebe-se que, a força das diferenças, perpassava pelo âmbito organizacional e se desencadeava no simbólico e no representativo. Por exemplo, aqueles que se destacava em suas manifestações artísticas, expressando suas qualidades e habilidades, se tornavam excepcionais e passavam a fazer parte de um grupo distinto, seleto, diferenciado, aos quais se tornavam privilegiados, sendo que, os que detinham conhecimentos sobre os processos culturais, eram por isso, elevados à categoria dos privilegiados. Em contrapartida, aqueles considerados sem atributos, que não tinham chances de competir e se destacarem em meio a aqueles grupos excepcionais por ausência de tais qualidades, eram excluídos daquele contexto social. A partir dessas classificações humanamente construídas, queria-se certamente, formar uma sociedade ideal para poucos, como se os escolhidos para fazer parte daquela conjuntura, fossem pessoas extraordinárias, pertencendo a um mundo diferente, sendo cortadas certas relações com outros indivíduos, sendo apenas mantidas as relações dominantes e dominados. No entanto, passou-se nesse instante, a haver uma visão diferenciada da pessoa, tudo isso culminou em uma organização social mais complexa com acentuadas diferenças entre os indivíduos, o que fica 
entendido como uma construção ideológica de grupos privilegiados, como se essa normatização fosse algo estabelecido por um poder divino.

Vale ressaltar que, a representação social e cultural é elaborada pelo próprio homem, dessa maneira, as ideologias culturais de um povo, tendem a ser reforçadas pelos grupos de convivência, isso acontece para que, possa manter vivos os traços culturais dominantes como argumentos reforçadores das diferenças entre os indivíduos. Para tanto, aquele que detém certo poder, não está satisfeito com o poder que tem, porém, busca freneticamente, a cada momento, reforçar o seu papel em determinado meio social, negligenciando aqueles que são intencionalmente desqualificados de toda "sorte". Nesse caso, as diferenças deixam de ser percebidas como algo positivo e passam a ser um fator de negação e exclusão, onde as questões entre os homens insistem em girar em torno da garantia do poder e do destaque entre eles. Não é de se estranhar que, em meio ao domínio da natureza e a subordinação de alguns indivíduos sobre outros, os grupos mais bem articulados passem a traçar planos estratégicos para sustentarem-se nos mais altos padrões de vida por meio da imposição dominante.

Sabe-se que com o passar do tempo, o homem foi se apropriando do que não era inerente a ele (a natureza), o que desencadeou, portanto, em querer assegurar a sua dominação e legitimá-la para não a perder para outros. Contudo, ao passar por um processo de maior conhecimento cultural e perceber como ocorriam as diferentes organizações entre pessoas, o homem, já não tinha a mesma concepção de antes em relação à ajuda recíproca, não obstante, começa a prevalecer os interesses dos mais fortes para a exploração dos mais fracos, ou seja, deveriam ter aqueles que possuíam bens pelo domínio da natureza e aqueles que precisavam se refrear a quem era dominante. Diante disso, a conquista e a dominação estavam acima de tudo, para tanto, foi preciso construir argumentos que justificassem como verdade inquestionável a nova forma de organização social. Diante da complexa situação, torna-se interessante fazer algumas análises e indagações sobre os "miseráveis da terra", a fim de evidenciar que, aqueles que não foram privilegiados em pertencerem a grupos arranjados, foram obrigados a si submeterem aos seus dominantes em diferentes situações, exercendo assim, atividades consideradas inferiores, fortalecendo a concepção de quem manda e quem obedece, a partir da representação simbólica na sociedade. Ao que diz respeito a essa situação:

O pensamento ideológico, portanto, é visto como (uma espécie de) resposta a esse desespero: "a ideologia é uma reação padronizada às tensões padronizadas de um papel social”. Ela fornece uma saída simbólica para as perturbações emocionais geradas pelo desequilíbrio social. Como se pode presumir que tais perturbações, de uma forma geral, são comuns a todos ou à maioria dos ocupantes de um determinado papel ou posição social, pode-se presumir também que as reações ideológicas a essas perturbações tenderão a 
ser semelhantes, uma similaridade apenas reforçada pelas coisas comuns pressupostas na "estrutura básica da personalidade" entre os membros de uma cultura particular, de uma classe ou categoria ocupacional (ROUSSEAU, 1999, p.114).

Diante da citação mencionada, torna-se bastante impactante, ao passo que, procura evidenciar que haviam tensões entre os privilegiados e os relegados, pois, era algo que realmente preocupava os poderosos, tornando-se necessário que o dominante se perpetuasse no poder a qualquer custo, mesmo que para isso, houvesse uma sentença bem elucidativa que mostrasse que ambos eram distintos, onde ficasse claro o lugar de cada um. Toda importância girava em torno da acumulação de bens e propriedades, o que significava um poder absoluto. É interessante ressaltar que, quando o homem passa a ter domínio da propriedade, ele não quer perdê-la de modo algum, mas para isso, era preciso que algo pudesse legitimar suas posses e favorecê-lo para que não viesse a perder a propriedade por quaisquer motivos. Portanto, é nesse momento de sensação de ameaça, que surge a sociedade baseada na proteção da propriedade, uma vez que a mesma passa a ser dirigida por leis, dando todo o apoio e poder necessário, bem como, as boas condições de sobrevivência para o "abastado", deixando o "desprovido" sem direitos e meios concretos de sobrevivência. Nessas condições, os despossuídos ficavam em situação mais lamentável do que se encontravam, simplesmente por não terem alguma coisa pelo que lutar, a não ser, prestar serviços para o dominante, de modo que viesse a garantir a sobrevivência. De fato, a construção e aplicação das leis consolidaram as desigualdades entre os homens, rompendo de uma vez portodas a ideia de que a natureza como outrora, era de todos, agora definitivamente tinha dono. Diante disso, Rousseau menciona:

Tal foi ou deve ter sido a origem da sociedade e suas leis, que criaram novos entraves para o fraco e novas forças para o rico, destruíram em definitivo a liberdade natural, fixaram para sempre a lei da propriedade e da desigualdade, de uma hábil usurpação fizeram um direito irrevogável e, para o lucro de alguns ambiciosos, sujeitaram daí para frente todo o gênero humano ao trabalho, a servidão e miséria (ROUSSEAU, 1999, p.222).

Diante da criação das leis, é notório que as desigualdades entre os homens e a injustiça social iam se alargando indiscutivelmente, pois, a defesa dos interesses dos privilegiados estava em pauta, que de acordo com suas conveniências, as leis contribuíram para que fossem assegurados os direitos e frutos das construções históricas dos poderosos, resultante do apossamento ilegal daquilo que não lhes pertenciam, ou seja, do que não foi criado por eles. Mas o processo de dominação, garantido pela lei, se direcionava para uma sociedade totalmente planejada em que a miséria de muitos manteria os benefícios de poucos privilegiados, portanto, a construção social não é natural, é simplesmente intencionada por quem se achava superior em vários aspectos e que por meio da estrutura posta, poderiam tirar muitos 
benefícios a seu favor. É de fundamental importância, destacar que, mais uma vez, o núcleo familiar foi imprescindível condição para que o homem tivesse uma concepção mais profunda do que significava ter propriedades e quais suas vantagens em adquiri-las. Por conta disso, houve uma competição desenfreada para sua aquisição de bens. Diante dessa situação, ressalta-se que, a lei deveria servir como garantia para proteger os benefícios daqueles que estava em situação favorável, em função daqueles que nada tinham, a não ser a servidão por opção.

\begin{abstract}
Ora, quando as heranças cresceram em números e em extensão a ponto de cobrirem todo o solo e tocarem-se umas nas outras, uma só puderam então progredir a expensas das outras, os supranumerários, que a fraqueza ou a indolência haviam impedido de adquiri-las por sua vez, tornados pobres sem nada terem perdido, porque, mudando tudo ao seu redor, apenas eles não mudado, foram obrigados a receber ou usurpar por sua subsistência da mão dos ricos; e dai começaram a nascer, conforme os diversos temperamentos de uns e de outros, a dominação e a servidão, ou a violência e as rapinas (ROUSSEAU, 1999, p. 218).
\end{abstract}

Perante a isso, concordo com Rousseau (1999) quando diz que é a partir desse momento em que a sociedade passa a viver sob um pacto social, justamente para conseguir manter os determinados privilégios de quem possui, nesse caso, as pessoas tidas como superiores, articulam o que vão oferecer aos excluídos, fazendo com que os relegados sintam-se dependente daqueles que detêm o poder e passem a aceitar na maioria das vezes, sem questionamento, uma falsa "bondade", que na verdade está carregada de intencionalidades. De fato, o interesse por leis que protegessem os "privilegiados" da terra, tinha uma intenção muito óbvia, que era manter as pessoas despossuídas sob o domínio dos poderosos, uma vez que, os abandonados eram uma ameaça muito perigosa, pois poderia haver confrontos em que os detentores de bens pudessem sair em serias consequências, uma vez que os excluídos eram minorias. Nessas condições, caso fosse percebido pelos despossuídos que algo estava errado na apropriação dos bens, isso poderia trazer serias consequências porque a maioria das pessoas que compunham a sociedade era de miseráveis e não percebiam as forças da construção das desigualdades para contestar e reverter à situação. Vale destacar que, a sociedade da época se encontrava com sérios problemas sociais, justamente pela apropriação irregular da natureza, isso fez com que acelerasse as providências para não quebrar o estado de natureza e garantir o estado de bem-estar estruturado dos abastados.

Não se pode negar o fato de que a busca pelo poder e dominação do homem foram fatores predominantes para que muitas das atrocidades cometidas pelo mesmo fizessem surgir, dentro da sociedade, diferentes classes sociais, com diferentes embates e interesses, sendo esses, defendidos pelos poderosos como direitos inquestionáveis. Diante da tentativa de compreender desde o estado de natureza do 
homem até sua dominação e acumulação de recursos naturais, Rousseau (1999) faz uma análise de todo um processo de articulação para justificar que os fundamentos das desigualdades entre os homens, não é natural, evidenciando que foi algo construído ao longo do tempo e não um fator como já foi dito estabelecido ou concebido por uma força superior. Mediante aos fatos apresentados, e dando sequência à discussão sobre as desigualdades, Marx (2012), se apropria do discurso da acumulação primitivas dos bens para trabalhar com as diferenças de classes sociais durante a modernidade. Essa conjuntura tem relações fortíssimas com o que aconteceu na apropriação e exploração da natureza, gerando dessa forma, os apropriados e expropriados dos meios de produção, configurando-se ainda, a poderosa sociedade capitalista. É importante ressaltar que, aqueles que no início da formação das propriedades dominaram por meios diversos, agora se reconfigurou por meio da apropriação dos meios de produção para formar uma nova hegemonia, tendo como base outra forma de dominação. Diante disso, pode-se afirmar que:

\begin{abstract}
A base do sistema capitalista é a separação radical do produtor e dos meios de produção. Para que esse sistema se estabeleça é necessário, que, em parte pelo menos, os meios de produção tenham sido anteriormente arrancados aos produtores que os empregavam em realizar a sua própria potência de trabalho, e que esses meios se encontrem igualmente detidos por produtos mercantis, que se empregam em especular com o trabalho alheio. $\mathrm{O}$ movimento histórico que dá por resultado o divórcio entre o trabalho e suas condições, os meios de produção, tal é o significado da acumulação primitiva (MARX, 2012, p. 2013).
\end{abstract}

Diante das mudanças que a sociedade veio sofrendo ao longo do tempo, o capitalismo foi ganhando espaço em todos os lugares, sendo que a grande mobilização era fazer com que os marginalizados ou aqueles pequenos proletários fossem aglutinados pelo grande capital detido na mão dos poderosos, sem condições nenhuma de sair desta composição, contribuindo assim, para que os desprovidos historicamente ficassem fora dos grupos dos privilegiados, tendo apenas como única "propriedade" a sua força de trabalho para ser explorada pelos donos dos meios de produção.

Diante das abordagens teóricas feitas e a partir do diálogo com alguns autores que tratam sobre a saída do homem do estado natural de natureza, pode-se perceber que, as injustiças e desigualdades sociais ao longo da história do homem não foi algo natural, mas sim, construída, arquitetada a partir da articulação do poder dominador, daquele que viu na posse da natureza o acumulo de um poder incontestável e de uma vida esplendorosa. Contudo, a superioridade de um indivíduo sobre o outro se deu anteriormente por meio do desenvolvimento do intelecto e da comunicação. Com a constituição familiar, o homem passa a se articular defendendo seus próprios interesses, rompendo assim, com a coletividade em que convivia, gerando dessa maneira a diferença entre os homens. Por fim, os fatores de desigualdade irão 
se reconfigurando ao longo do tempo chegando até a modernidade, cujas diferenças sociais se constituíram pela posse de bens e detenção do capital nas mãos de pou$\cos$.

\section{Referências bibliográficas}

CASTEL, Robert. As metamorfoses da questão social: uma crônica do salário. Robert Castel. Tradução de Iraci D. Poleti. 11. ed - Petrópolis, RJ: Vozes, 2013.

ENGELS, Friedrich. A Origem da Família, da Propriedade Privada e do Estado. Trabalho relacionado com as investigações de L. H. Morgan. 9ª. ed - Editora Civilização Brasileira S.A, Rio de Janeiro, 1984.

GEERTZ, Clifford, 1926. A interpretação das culturas. 1. ed. [Reimpr] - Rio de Janeiro: LTC, 2013.

LARAIA, Roque de Barros, 1932. Cultura: um conceito antropológico. Rio de Janeiro: Zahar, 1986.

MARX, Karl. O capital. Condensação de Gabriel Deville. São Paulo: EDIPRO, 3ª ED. $1^{\mathrm{a}}$ REIMPR, 2012.

ROUSSEAU, Jean-Jacques. Discurso sobre a origem e os fundamentos da desigualdade entre os homens. Tradução de Maria Ermantina Galvão. Cronologia e introdução de Jacques Roger - 2 ed. São Paulo: Martins Fontes, 1999.

O contrato social ou Princípios do direito político. Tradução de Ciro Mioranza. São Paulo: Escala Educacional, 2006.

Submissão: 20.08.2016 / Aceite: 30.09.2016 